\title{
Shear performance of RC beams with spatial distribution of bond deterioration in longitudinal tension bars
}

\author{
Xue xin $^{1, \text { a }}$, Yang cheng ${ }^{1, b}$ and Zhang Hanyin ${ }^{1, c}$ \\ ${ }^{1}$ School of Architecture and Civil Engineering, Xiamen University, Xiamen 361005, P.R. China \\ axuexin@xmu.edu.cn, ${ }^{b} 597210830 @ q q . c o m,{ }^{c} 348480141 @ q q . c o m$
}

Keywords: Bond deterioration, Shear performance, spatial distribution, Tie-arch mechanism.

Abstract. This paper carried out an experimental investigation on the effects of spatial distribution of bond degradation on the load-carrying mechanism and failure mode of $\mathrm{RC}$ beams. Bond degradation was simulated using artificial method and shear performance was investigated through three-point loading tests. Test results indicate that: It was more dangerous for $\mathrm{RC}$ beams have the bond deterioration area near the supporting position than in the vicinity of middle portions; compared with the control specimen placed with ordinary steel bars, the specimens using the steel bars with surface coating exhibited the same shear behavior.

\section{Introduction}

The corrosion of embedded steel bars is one of the most critical factors that may have adverse effect on the structural performance of RC structures. Once steel bars corrode, the following subsequences occur: cross-sectional area loss of steel bars; generation of corrosion cracks in concrete; and deterioration in bond strength between steel bars and the surrounding concrete. Among them, the corrosion might cause the most obvious decline in bond strength [1-2]. Published research pointed out that when the average corrosion mass loss ratio reached a level of $20 \% \sim 30 \%$, the bond strength may even decrease to $20 \%$ that of the sound case.

For the shear performance of RC beams, the bond deterioration of longitudinal tension bars may cause the reduction of the stiffness and change the failure mode. XH Wang et [3] pointed out that there are no diagonal cracks occurring within the zones where the bond strength deteriorated severely, and the failure mode became brittle when the corrosion level was high. XH Gao [4] suggested that the partial unbound of longitudinal tension bars could change the failure mode and enhanced the ductility of RC beams. Kakuda et [5] pointed out that the load-carrying mechanism changed with the corrosion level and corrosion location of longitudinal tension bars. The study of Marakami et [6] indicated that the corrosion of longitudinal bar led to the enhancement of tie-arch action of RC beams, but when the severe corrosion occurred in the vicinity of supporting zone, the tie-arch action could no longer sustain shear load due to the premature anchorage failure of longitudinal tension bars. Published research showed that the spatial distribution of bond degradation has a significant impact on the shear load-carrying mechanism, but there aren't unified cognition and conclusions, so it is worth to taking a further study.

Given the above mentioned background, this paper carried out an experimental investigation on the effect of spatial bond deterioration on the shear performance. In this study, the bond deterioration was simulated using artifitial method, surpposing that the bond strength deteriorated dramatically due to the severe corrosion of longitudinal tension bars.

\section{Experimental Details}

Specimen Details. The dimensions and steel bar placements of the specimen are shown in Fig. 1 and Table 1. The cross-sections of the specimens were $160 \mathrm{~mm} \times 250 \mathrm{~mm}$, the shear span to effective depth a/d was 3.0. Rebar D22 (HRB400 in Chinese specification) was used for the longitudinal tension bars. Round bar $\varphi 6$ (HPB235 in Chinese specification) was used for the stirrups. The experimental parameters were the spatial distributions of bond deterioration and the changes of the entire bond 
strength of longitudinal tension bars. The spatial bond deterioration was simulated using the following method: the spacing between the projections on the rebar surface was firstly filled up with paraffin wax to dramatically decrease the interlock friction effect between rebar and the surrounding concrete, and then the rebar was wrapped with glass paper. The effect of the change of the entire bond strength of longitudinal tension bars was investigated by introducing surface coated steel bars. The types of surface coated steel bars are shown in Table 1. The bond strength of epoxy coated steel bars was slightly lower, but was more than $85 \%$ that of the ordinary steel bars. Due to the coarse surface of galvanized steel bars, the bond strength should be not less than that of the ordinary steel bars. Since it was coated with epoxy resin on the galvanized layer, the bond strength of the composite coated steel bars surface was lowest. The mechanical properties of all long longitudinal bars were the same. The mix proportion of concrete is shown in Table 2, and the 28 day compression strength of concrete was $47 \mathrm{~N} / \mathrm{mm}^{2}$.
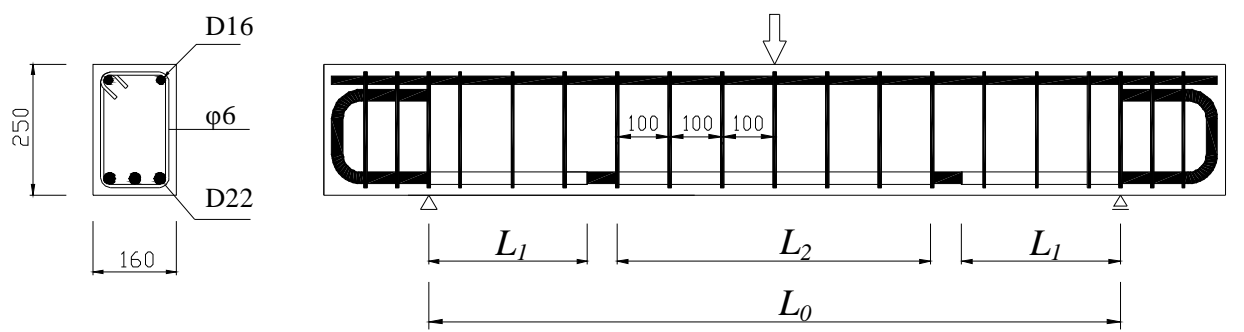

Fig. 1 Dimension and reinforcement details for specimens

Table 1. Experimental Details

\begin{tabular}{|c|c|c|c|c|c|c|}
\hline \multirow{2}{*}{ Specimens } & \multicolumn{3}{|c|}{ Bond deterioration Zone (mm) } & \multirow{2}{*}{$\begin{array}{c}\text { Type of } \\
\text { longitudinal bars }\end{array}$} & \multirow{2}{*}{\multicolumn{2}{|c|}{ Reference }} \\
\hline & $L_{1}$ & $L_{2}$ & $L_{0}$ & & & \\
\hline B3.0-01 & --- & --- & --- & \multirow{4}{*}{ Ordinary steel bars } & \multirow{4}{*}{ Ordinary steel } & \multirow{4}{*}{ Epoxy coated steel } \\
\hline B3.0-ma & 600 & --- & -- & & & \\
\hline $\mathrm{B} 3.0-\mathrm{mb}$ & -- & 300 & --- & & & \\
\hline $\mathrm{B} 3.0-\mathrm{mc}$ & --- & --- & 1320 & & & \\
\hline B3.0-me & --- & --- & --- & Epoxy coated steel bars & \multirow[b]{3}{*}{ Galvanizing steel } & \multirow[b]{3}{*}{ Composite coatedsteel } \\
\hline B3.0-md & --- & --- & --- & Galvanizing steel bars & & \\
\hline B3.0-mf & -- & --- & -- & Composite coated steel bar & & \\
\hline
\end{tabular}

Table 2. Mix proportion of concrete

\begin{tabular}{c|c|c|c|c|c|c}
\hline \multirow{2}{*}{ W/C } & \multirow{2}{*}{ s/a } & \multicolumn{5}{|c}{ Unit(kg/m3) } \\
\cline { 3 - 7 } & & Cement & Water & Sand & Gravel & Admixture \\
\hline 0.4 & 0.42 & 398 & 159 & 783 & 1064 & 5.37 \\
\hline
\end{tabular}

Loading Test. After the curing period of 28 days, the specimens were subjected to the loading tests under simply supported conditions, as shown in Fig. 2. A vertical load was applied at the mid span with a displacement increment of $0.3 \mathrm{~mm} /$ minute. The application of the load was monitored using a load cell, and the deflection was measured using 5 linear variable differential transformers displacement transducers (LVDT) placed beneath the soffit of specimens. The deflection at mid-span was used to investigate load-displacement behavior. The opening of the critical shear crack was measured using a 
visual crack comparator during the loading tests. In this paper, the critical crack refers to the diagonal crack that caused the failure of the beams.

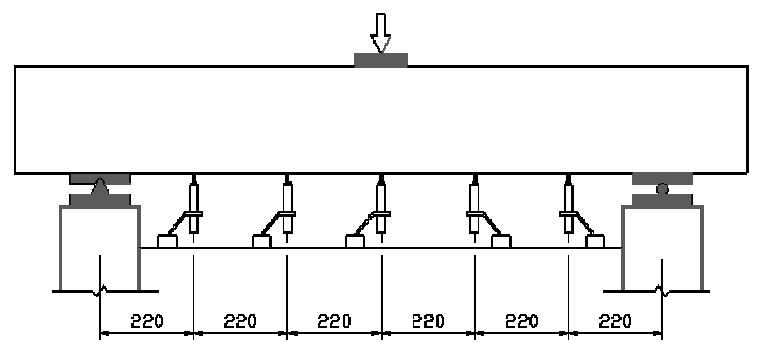

Fig. 2 Loading test details

\section{Test results and discussion}

Effect of Spatial Bond Deterioration. The test results was summarized in the table 3, in which $P_{c}$ refers to the load when the first diagonal crack appeared and MWC refers to the maximum width of critical diagonal cracks.

Table 3 Test results

\begin{tabular}{c|c|c|c}
\hline Specimens & $P_{c}(\mathrm{kN})$ & $P_{\text {test }}(\mathrm{kN})$ & $\mathrm{MWC}(\mathrm{mm})$ \\
\hline B3.0-01 & 103.9 & 309.8 & 1.9 \\
\hline B3.0-ma & 162 & 291.8 & 2.5 \\
\hline B3.0-mb & 62.1 & 227.1 & 3 \\
\hline B3.0-mc & 240 & 314.2 & --- \\
\hline B3.0-md & 105 & 292.7 & 2.5 \\
\hline B3.0-me & 125 & 306.4 & 1.2 \\
\hline B3.0-mf & 99 & 299.6 & 1.4 \\
\hline
\end{tabular}

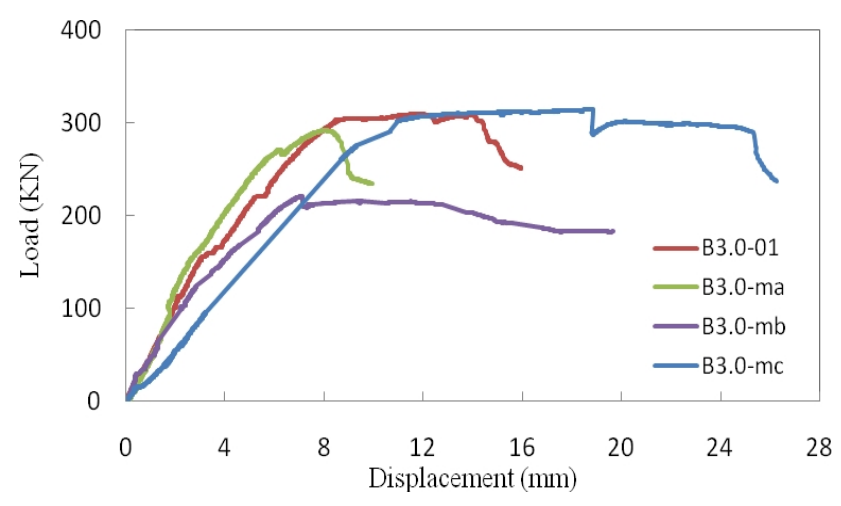

Fig. 3 Load displacement behavior

Fig. 3 shows the load-deflection behavior of the specimens. Fig. 4 and Fig. 5 show the crack pattern at failure and the crack opening behavior of the critical crack respectively. Except for B3.0-mc and B3.0-mb, all other specimens failed in shear compression. The shear strength of B3.0-ma was slightly lower, but the stiffness was slightly larger than that of the control beam B3.0-01. The crack opening behavior and the crack pattern of B3.0-ma is similar to that of the control specimen. The failure mode of B3.0-mb was somewhat similar to diagonal tension failure, and the shear strength and stiffness decreased significantly than the control beams. During the loading process of B3.0-mb, the first diagonal crack appeared at the early stage and developed to the loading position. As the load increased, the second diagonal closed to the mid-span appeared. Finally, the inner part between the two diagonal cracks formed an inner arch, and with the aid of constrain of the stirrups, this inner arch continued to sustain applied load by for some while Although the failure of the B3.0-mb showed some ductility, but as shown in Fig. 5, the opening of the critical diagonal crack developed quickly during the loading test and severe spalling of cover concrete occurred during the post-peak process.

Due to the substantial decline of the bond strength of the whole longitudinal tension bars, there was no diagonal crack appeared within the shear span of B3.0-mc. Since the bond strength of the whole longitudinal tension bars decreased, the load applied to B3.0-mc was supported by "tie-arch" mechanism, which was different from the "beam mechanism" developed in control beam, and failed in flexure. The strength of B3.0-mc was higher than the control specimen. Compared with other specimens, the stiffness of B3.0-mc decreased most dramatically due to the substantial weakening of "tension-stiffness". 


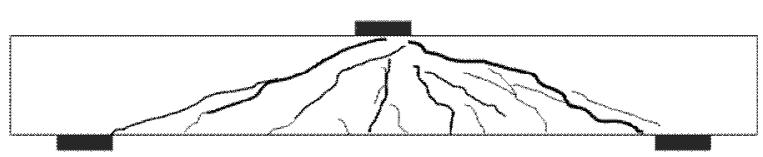

(a) B3.0-01

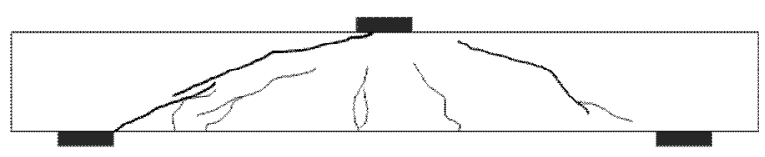

(b) B3.0-ma

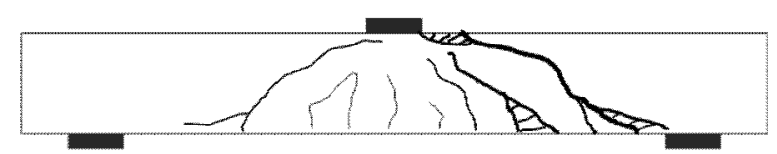

(c) B3.0-mb

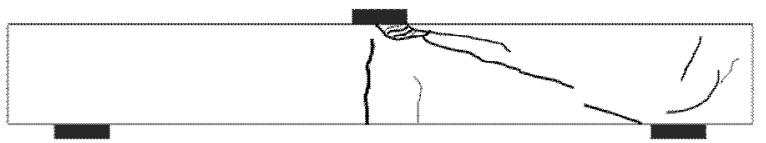

(d) B3.0-mc

Fig. 4 Crack pattern at failure

Fig. 6 shows the comparison of the shear strength. Compared with the control specimen, the shear strength of B3.0-ma decreased slightly by $6 \%$, the corresponding value of B3.0-mb was $27 \%$. This indicates that, compared with the mid-span location, bond deterioration developing near the supporting position had more adverse effect on the shear strength of RC beam.

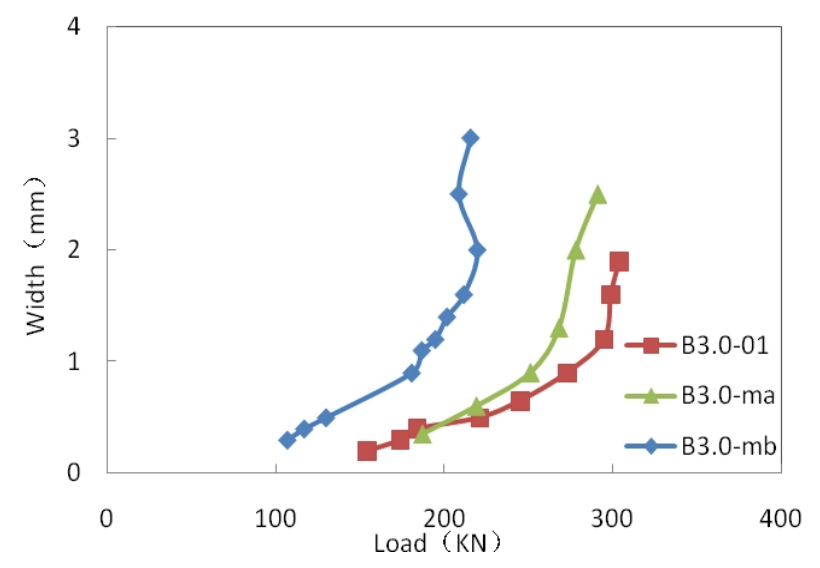

Fig. 5 Crack-opening behavior

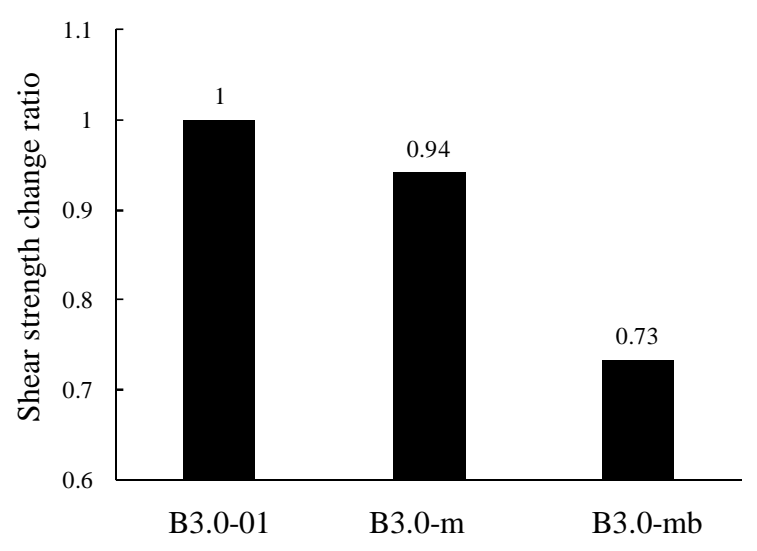

Fig. 6 Comparison of shear strength

Influence of entire bond strength of Longitudinal Tension Bars. Fig. 7 shows load displacement behavior. All the specimens showed in the figure failed in shear compression. It can be observed that, compared with the control specimen, the stiffness of the specimens using surface coating steel bars was slightly larger, but the shear strength was almost the same. B3.0-me showed less ductility than that of the other specimens. This might be caused by the bond deterioration of the longitudinal tension bars caused by epoxy coating.

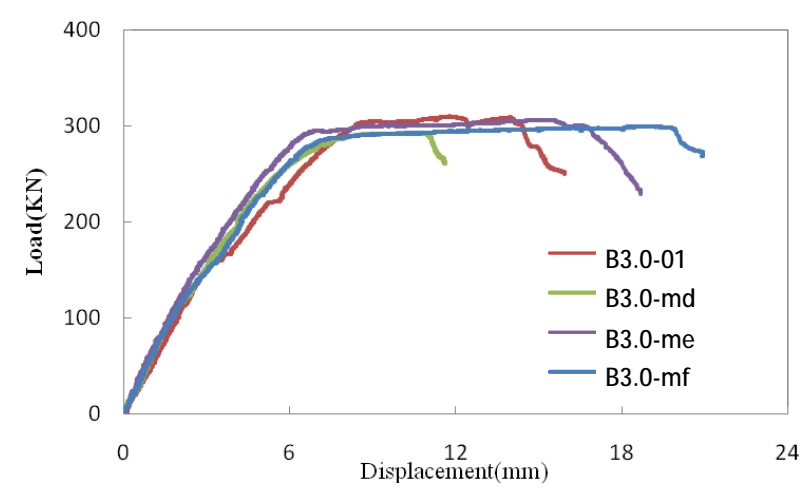

Fig. 7 Load-displacement behavior

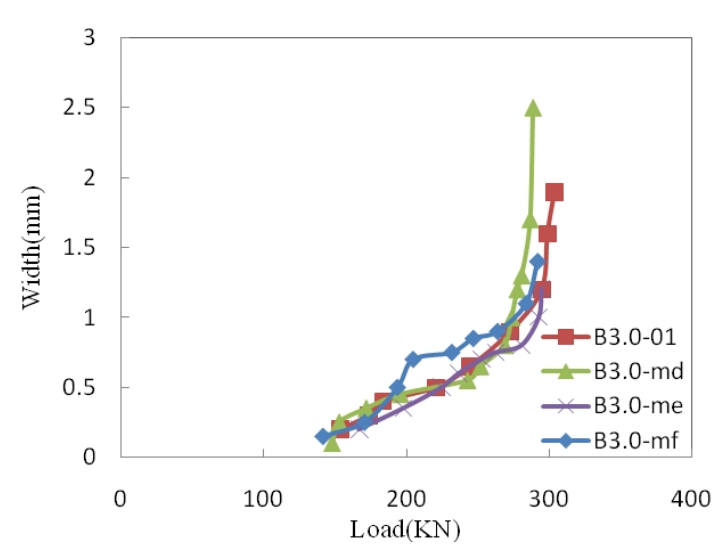

Fig. 8 Crack-opening behavior 


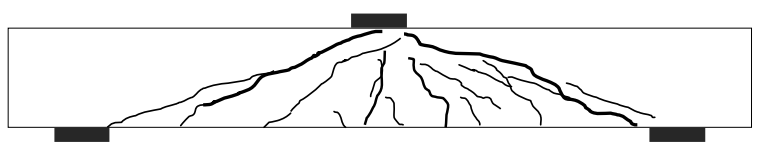

(a) B3.0-01

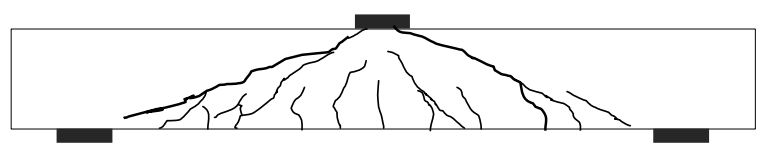

(b) B3.0-md

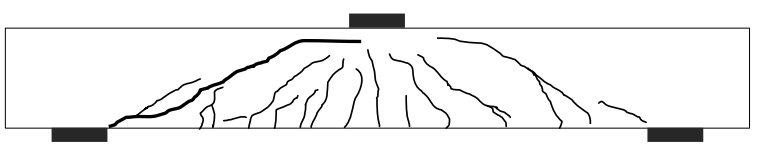

(c) B3.0-me

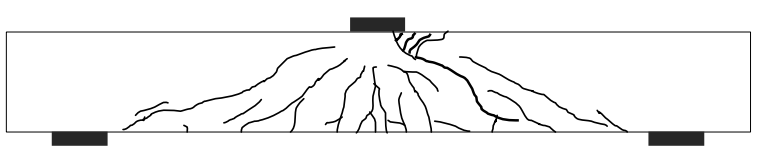

(d) B3.0-mf

Fig. 9 Crack pattern at failure

Fig. 8 and Fig. 9 show the crack opening behavior of the critical crack and the crack pattern at failure respectively. There was little difference in the opening behavior of the critical crack and the crack distribution at failure between the specimens using surface coating steel bars and the control specimen. Test results indicated that the surface coating of the longitudinal tension bars had little effect on the shear performance of RC beams. This was due to little change of the bond strength of surface coating steel bars.

\section{Conclusions}

This paper carried out an experimental investigation on the spatial distribution of bond deterioration on the shear performance of RC beams. Within the scope of this study, the following conclusions can be drawn.

1) The spatial distribution of bond deterioration of longitudinal tension bars affected the shear performance of RC beams. The RC beams with the bond deterioration area near the supporting position exhibited more reduction in stiffness and shear strength than that is the case for the bond deterioration area in the vicinity of middle portions.

2) Due to the little change of the bond strength of the surface coating steel bars, the using surface coating steel as longitudinal tension bars had little effect on the shear performance of RC beams.

\section{Acknowledgements}

This work was financially supported by the Scientific Research Foundation for Returned Overseas and Natural Science Foundation of Fujian Province of China (2013J01207). The steel bars use for the longitudinal tension bars in this study were provided by The writers gratefully acknowledge the support provided by XiaMen New Steel Metal Products Co., Ltd for providing the surface coated steel bars in the test program.

\section{References}

[1] A.A. Almusallam, A.S. Al-Gahtani, A.R. Aziz, Rasheeduzzafar: Construction and Building Materials Vol. 10 (1996), p. 123

[2] X. Xue, H. Seki, S. Hiromori: Journal of JSCE Vol. 65 (2009), P. 161

[3] X.H. Wang, X.H. Gao, B. Li, B.R. Deng: Constr. Build. Mater Vol. 25 (2011), P. 1812

[4] B. Li, X.H. Gao, L.F. Shi: China Concrete and Cement Products Vol. 6 (2010), P. 60

[5] M. Kakuda, K. Watanabe, J. Niwa:, Proceedings of the JCI Vol. 31 (2009), P. 1561

[6] Y. Murakami, W. Dong, E. Oshita: Journal of JSCE Vol. 67 (2011), p. 605 